Proceedings of the 42th "Jaszowiec" International School and Conference on the Physics of Semiconductors, Wisła 2013

\title{
Influence of Cr-Substitution on the Electrical Properties of $\mathrm{Fe}_{1-x} \mathrm{Cr}_{x} \mathrm{VSbO}_{6}$
}

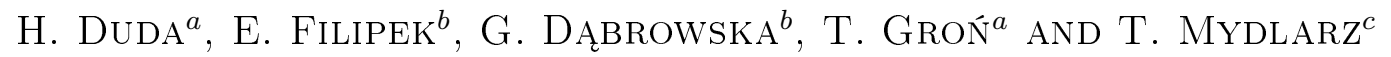

${ }^{a}$ University of Silesia, Institute of Physics, Uniwersytecka 4, 40-007 Katowice, Poland

${ }^{b}$ West Pomeranian University of Technology, Szczecin, Department of Inorganic and Analytical Chemistry al. Piastów 42, 71-065 Szczecin, Poland

${ }^{c}$ International Laboratory of High Magnetic Fields and Low Temperatures, Gajowicka 95, 53-529 Wrocław, Poland

$\mathrm{Fe}_{1-x} \mathrm{Cr}_{x} \mathrm{VSbO}_{6}$ solid solution is semiconductor with the activation energy decreasing both in the intrinsic and extrinsic conductivity temperature regions as the $\mathrm{Cr}$-content increases. The $n$-type conduction is observed for Fe-richer samples while a change of the Seebeck coefficient (from $n$ to $p$ ) - for Cr-richer ones. Magnetic isotherms for all samples of solid solution under study are characteristic of the universal Brillouin function, indicating paramagnetic response. These effects are discussed within the framework of the appearance of the mixed valence of both $\mathrm{Fe}$ and $\mathrm{Cr}$ ions.

DOI: $10.12693 /$ APhysPolA.124.833

PACS: 72.20.Pa, 72.80.Ga, 75.20.-g

\section{Introduction}

In the recent years, an intensification has been observed in the field of research on multicomponent oxide system, which is frequently aimed at obtaining new materials of interesting functional properties. The compounds with general formula $\mathrm{M}^{\prime} \mathrm{MSbO}_{6}$, where $\mathrm{M}^{\prime}=\mathrm{Fe}$, $\mathrm{Cr}, \mathrm{Al} ; \mathrm{M}=\mathrm{V}, \mathrm{Ru}$, Ti have been reported and characterized recently because of their interesting electrical, magnetic and catalytic properties [1-7]. Among these $\mathrm{FeVSbO}_{6}$ and $\mathrm{CrVSbO}_{6}$ are isostructural and crystallize in the tetragonal system and possess a rutile-type structure (space group $P 4_{2} / m n m, Z=2$ ) $[1,4,5]$. A new solid solution with chemical formula $\mathrm{Fe}_{1-x} \mathrm{Cr}_{x} \mathrm{VSbO}_{6}$ forms also a tetragonal structure of rutile-type in the whole components concentration range $(0.0<x<1.0)$ of the $\mathrm{FeVSbO}_{6}-\mathrm{CrVSbO}_{6}$ system [8]. The structural investigations showed that the contraction of $\mathrm{Fe}_{1-x} \mathrm{Cr}_{x} \mathrm{VSbO}_{6}$ solid solution crystal lattice increased with increasing degree of $\mathrm{Cr}^{3+}$ ion incorporation into the $\mathrm{FeVSbO}_{6}$ structure $[8]$.

This paper presents the electrical properties of $\mathrm{Fe}_{1-x} \mathrm{Cr}_{x} \mathrm{VSbO}_{6}$ solid solutions as well as the magnetic isotherms measured in the magnetic field up to $14 \mathrm{~T}$.

\section{Experimental details}

The samples for the synthesis of solid solutions $\mathrm{Fe}_{1-x} \mathrm{Cr}_{x} \mathrm{VSbO}_{6}$ were prepared from suitable mixtures of oxides and from the separately synthesized compounds: $\mathrm{FeVSbO}_{6}$ and $\mathrm{CrSbVO}_{6}$ in air and in argon atmosphere by the conventional solid-state reaction technique according to the equations given in the work [8]:

$$
\begin{aligned}
& (1-x) \mathrm{Fe}_{2} \mathrm{O}_{3(\mathrm{~s})}+x \mathrm{Cr}_{2} \mathrm{O}_{3(\mathrm{~s})}+\mathrm{V}_{2} \mathrm{O}_{5(\mathrm{~s})}+\mathrm{Sb}_{2} \mathrm{O}_{4(\mathrm{~s})} \\
& \left.\quad=2 \mathrm{Fe}_{1-x} \mathrm{Cr}_{x} \mathrm{VSbO}_{6(\mathrm{~s} . \mathrm{s} .}\right)
\end{aligned}
$$

and

$$
\begin{aligned}
& (1-x) \mathrm{FeVSbO}_{6(\mathrm{~s})}+x \mathrm{CrVSbO}_{6(\mathrm{~s})} \\
& \quad=\mathrm{Fe}_{1-x} \mathrm{Cr}_{x} \operatorname{VSbO}_{6(\text { s.s. })} .
\end{aligned}
$$

Monophase samples containing the solid solution were characterized by XRD and SEM methods. Figure 1 presents a fragment of a diffraction pattern and Fig. 2 - SEM image of the $\mathrm{Fe}_{1-x} \mathrm{Cr}_{x} \mathrm{VSbO}_{6}$ solid solution for

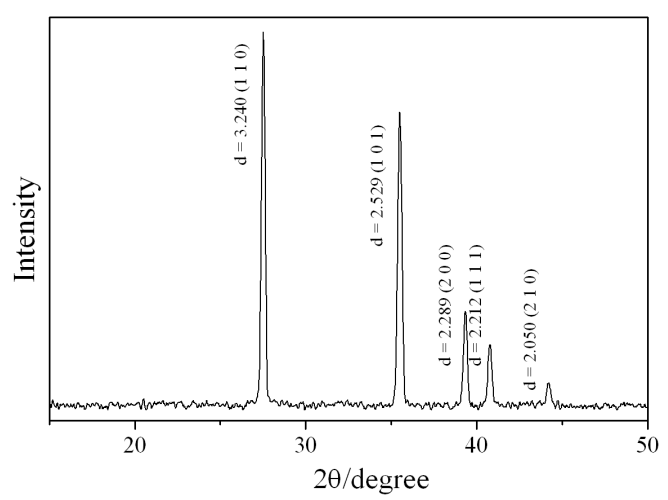

Fig. 1. XRD pattern of the $\mathrm{Fe}_{0.5} \mathrm{Cr}_{0.5} \mathrm{VSbO}_{6}$ solid solution.

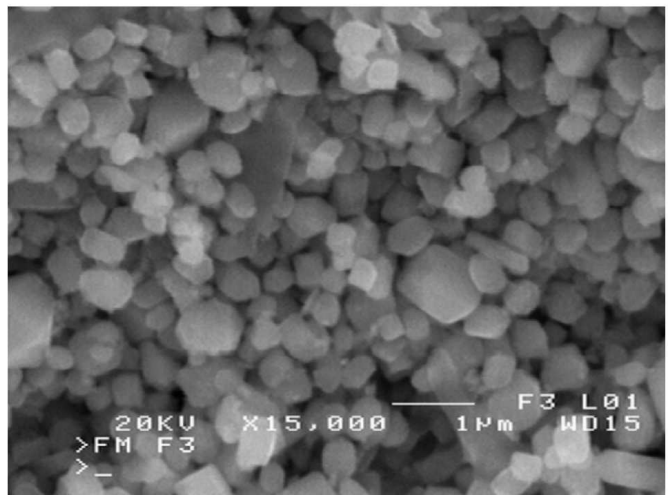

Fig. 2. SEM images of $\mathrm{Fe}_{0.5} \mathrm{Cr}_{0.5} \mathrm{VSbO}_{6}$. 
$x=0.5$. Obtained results were almost identical to described in the paper [8].

The electrical conductivity $\sigma(T)$ of $\mathrm{Fe}_{1-x} \mathrm{Cr}_{x} \mathrm{VSbO}_{6}$ has been measured with the aid of the DC method in the temperature range 76-400 K using a KEITHLEY 6517B Electrometer/High Resistance Meter. The thermoelectric power $S(T)$ was measured in the temperature range 300-600 K with the aid of a Seebeck Effect Measurement System (MMR Technologies, Inc., USA). The magnetization isotherm was measured in the zero-field-cooled mode at $4.2 \mathrm{~K}$ using a vibrating sample magnetometer with a step motor in applied external fields up to $14 \mathrm{~T}$ [9].

\section{Results and discussion}

The results of $\sigma(T)$ measurements presented in Fig. 3 for $\mathrm{Fe}_{1-x} \mathrm{Cr}_{x} \mathrm{VSbO}_{6}$ (where $x=0.0,0.05,0.25,0.5,0.75$, 0.9 , and 1.0) showed a typical Arrhenius behaviour with two values of the activation energy in the temperature range $76-400 \mathrm{~K}$. The activation energy $E_{\mathrm{a}}$, determined from the formula $\sigma=\sigma_{0} \exp \left(-E_{\mathrm{a}} / k T\right)$, decreases for both the intrinsic and extrinsic conductivity temperature regions from $0.11 \mathrm{eV}$ for $x=0.0$ to $0.05 \mathrm{eV}$ for $x=1.0$ and from $0.33 \mathrm{eV}$ for $x=0.0$ to $0.27 \mathrm{eV}$ for $x=1.0$, respectively. In general, $\sigma(T)$ increases as the $\mathrm{Cr}$-content increases.

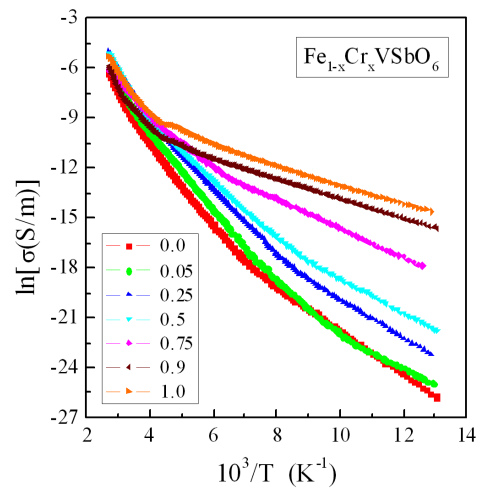

Fig. 3. Electrical conductivity $(\ln \sigma)$ vs. reciprocal temperature $\left(10^{3} / T\right)$ for $\mathrm{Fe}_{1-x} \mathrm{Cr}_{x} \mathrm{VSbO}_{6}$.

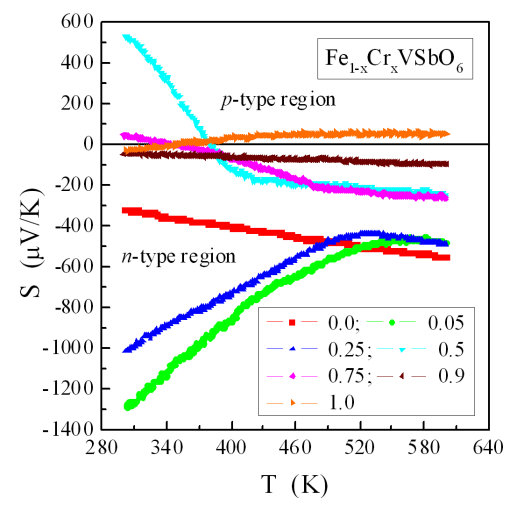

Fig. 4. Thermoelectric power $S$ vs. temperature for $\mathrm{Fe}_{1-x} \mathrm{Cr}_{x} \mathrm{VSbO}_{6}$.

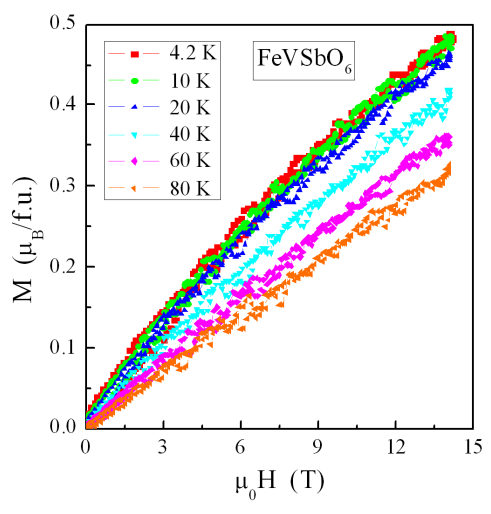

Fig. 5. Magnetization $M$ vs. magnetic field $\mu_{0} H$ at 4.2 , 10, 20, 40, 60, and $80 \mathrm{~K}$ for $\mathrm{FeVSbO}_{6}$.

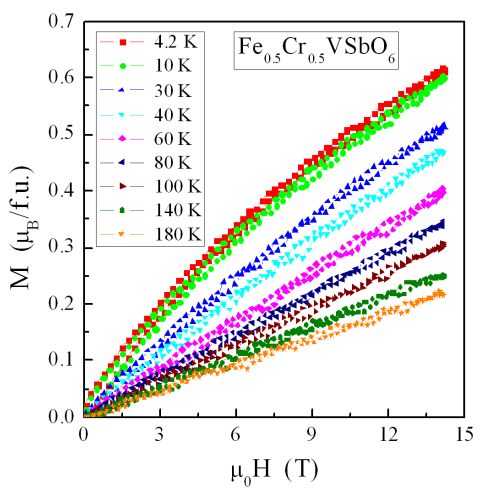

Fig. 6. Magnetization $M$ vs. magnetic field $\mu_{0} H$ at $4.2,10,30,40,60,80,100,140$, and $180 \mathrm{~K}$ for $\mathrm{Fe}_{0.5} \mathrm{Cr}_{0.5} \mathrm{VSbO}_{6}$.

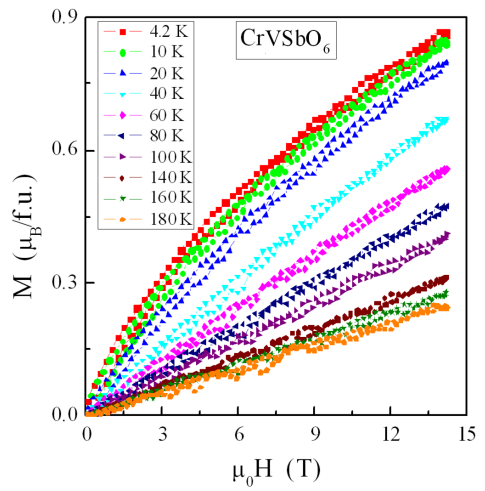

Fig. 7. Magnetization $M$ vs. magnetic field $\mu_{0} H$ at $4.2,10,20,40,60,80,100,140,160$, and $180 \mathrm{~K}$ for $\mathrm{CrVSbO}_{6}$. 
The results of $S(T)$ measurements presented in Fig. 4 for $\mathrm{Fe}_{1-x} \mathrm{Cr}_{x} \mathrm{VSbO}_{6}$ solid solutions revealed $n$-type conduction for Fe-richer samples while a change of the Seebeck coefficient (from $n$ to $p$ ) is observed for Cr-richer ones. In general, $S(T)$ increases as the Cr-content increases. For all the solid solutions under study a rather well defined linear slope of $S(T)$ (diffusion thermopower) which extrapolates to $(0,0)$ was found. It means that the Cr-substitution does not essentially influence on the diffusion electronic transport at high temperatures but this effect is larger at lower temperatures.

The results of magnetic measurements presented in Figs. 5-7 for $\mathrm{Fe}_{1-x} \mathrm{Cr}_{x} \mathrm{VSbO}_{6}$ (where $x=0.0,0.5$ and 1.0) showed typical behaviour for paramagnets. The magnetic isotherms with zero coercivity and remanence do not reach the saturation magnetization in the magnetic field up to $14 \mathrm{~T}$. At low temperatures the shape of magnetic isotherms is characteristic of the universal Brillouin function while at higher temperatures $M$ vs. $\mu_{0} H$ is linear. It indicates paramagnetic response [10]. With increasing Cr-content in a sample the magnetic moment at $14 \mathrm{~T}$ increases from $0.49 \mu_{\mathrm{B}} /$ f.u. for $x=0.0$ via $0.63 \mu_{\mathrm{B}} /$ f.u. for $x=0.5$ to $0.88 \mu_{\mathrm{B}} /$ f.u. for $x=1.0$.

\section{Conclusions}

The results mentioned above suggest that the changes of the electrical conductivity may be connected with the appearance of the mixed valence of $\mathrm{Fe}$ ions as it was observed in $\mathrm{Fe}_{2} \mathrm{~V}_{4} \mathrm{O}_{13}$ doped with Mo $[11,12]$. On the other hand, the increase of both the intrinsic conductivity and the Seebeck coefficient can come from the charge compensation linked with the recombination of the current carriers, which takes place throughout the localized states in the forbidden band [13]. The nature of these states can be linked with the existence of the structure defects and the grain-boundaries with the depletion layers of the adjacent grains. From the other side simultaneous growth of the magnetic moment as well as the electrical conduction, particularly at low temperatures can point out to the presence of chromium ions with the different valence [13], as it was for example observed in $\mathrm{Zn}_{1-x} \mathrm{Cu}_{x} \mathrm{Cr}_{2} \mathrm{Se}_{4}$ [13], $\mathrm{Zn}_{x} \mathrm{Cu}_{y} \mathrm{Cr}_{z} \mathrm{Se}_{4}$ [14] and $\mathrm{Cu}_{x} \mathrm{Co}_{y} \mathrm{Cr}_{z} \mathrm{Se}_{4}$ [15] spinel series.

\section{Acknowledgments}

This work was partly supported by Ministry of Scientific Research and Information Technology (Poland) and funded from science resources: No. 1S-0300-500-1-05-06.

\section{References}

[1] J. Isasi, M.L. Veiga, A. Jerez, M.L. Lopez, C. Pico, J. Mater. Chem. 1, 1027 (1991).

[2] J. Isasi, M.L. Veiga, C. Pico, J. Mater. Chem. 5, 871 (1995).

[3] J. Isasi, M.L. Veiga, C. Pico, J. Mater. Sci. Lett. 15, 1022 (1996).

[4] E. Filipek, G. Dąbrowska, J. Mater. Sci. 42, 4905 (2007).

[5] E. Filipek, G. Dąbrowska, M. Piz, J. Alloys Comp. 490, 93 (2010).

[6] J. Typek, N. Guskos, E. Filipek, M. Piz, Rev. Adv. Mater. Sci. 23, 196 (2010).

[7] J. Typek, N. Guskos, E. Filipek, J. Non-Cryst. Solids 354, 4494 (2008).

[8] E. Filipek, G. Dąbrowska, J. Alloys Comp. 523, 102 (2012).

[9] V.I. Nizhankovskii, L.B. Lugansky, Meas. Sci. Technol. 18, 1533 (2007).

[10] S.A. Majetich, J.O. Artman, M.E. McHenry, N.T. Nuhfer, S.W. Stanley, Phys. Rev. B 48, 16845 (1993).

[11] T. Groń, J. Krok, M. Kurzawa, J. Walczak, J. Magn. Magn. Mater. 54-57, 1301 (1986).

[12] J. Krok, T. Groń, J. Walczak, M. Kurzawa, J. Kuriata, T. Mydlarz, J. Mater. Sci. Lett. 6, 692 (1987).

[13] T. Groń, H. Duda, J. Warczewski, Phys. Rev. B 41, 12424 (1990).

[14] T. Groń, A. Krajewski, H. Duda, P. Urbanowicz, Physica B 373, 245 (2006).

[15] T. Groń, S. Mazur, H. Duda, J. Krok-Kowalski, E. Maciążek, J. Alloys Comp. 467, 102 (2009). 